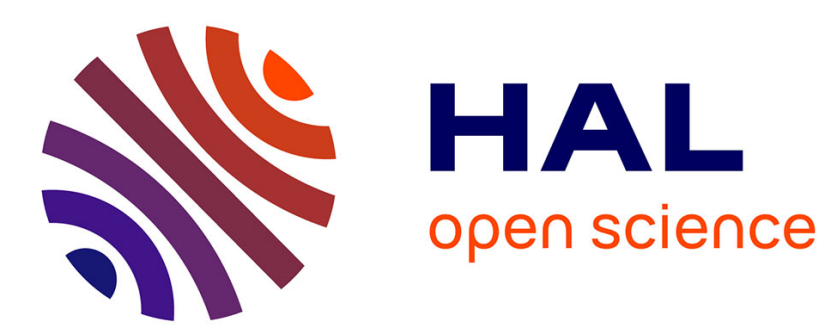

\title{
Observer-Based Optimal Control of Dry Clutch Engagement
}

P. J. Dolcini, Carlos Canudas de Wit, H. Béchart

\section{To cite this version:}

P. J. Dolcini, Carlos Canudas de Wit, H. Béchart. Observer-Based Optimal Control of Dry Clutch Engagement. Oil \& Gas Science and Technology - Revue d'IFP Energies nouvelles, 2007, 62 (4), pp.615-621. 10.2516/ogst:2007053 . hal-02005731

\section{HAL Id: hal-02005731 \\ https://hal.science/hal-02005731}

Submitted on 4 Feb 2019

HAL is a multi-disciplinary open access archive for the deposit and dissemination of scientific research documents, whether they are published or not. The documents may come from teaching and research institutions in France or abroad, or from public or private research centers.
L'archive ouverte pluridisciplinaire HAL, est destinée au dépôt et à la diffusion de documents scientifiques de niveau recherche, publiés ou non, émanant des établissements d'enseignement et de recherche français ou étrangers, des laboratoires publics ou privés. 


\title{
Observer-Based Optimal Control of Dry Clutch Engagement
}

\author{
P.J. Dolcini ${ }^{1}$, C. Canudas de $\mathrm{Wit}^{2}$ and H. Béchart ${ }^{1}$ \\ 1 Centre Technique Renault de Lardy, 1 allée Cornuel, 91510, Lardy - France \\ 2 Laboratoire d'Automatique de Grenoble, UMR CNRS 5528, ENSIEG-INPG, BP 46, 38402 St Martin d'Hères, Lardy - France \\ e-mail: pietro.dolcini@renault.com - hubert.bechart@renault.com - carlos.canudas-de-wi@@lag.ensieg.inpg.fr
}

\begin{abstract}
Résumé - Commande optimale de la synchronisation de l'embrayage par observateur — La majorité des boîtes de vitesses robotisées en série ont une commande de l'embrayage sec basée sur des tables de valeurs soigneusement choisies afin d'assurer une synchronisation sans à-coups mais avec un long temps de patinage lors des décollages. Cet article propose, à la place, une stratégie en deux parties : une première partie en boucle ouverte basée sur des tables de valeurs assurant un faible temps de patinage couplée à une deuxième phase assurant une synchronisation sans à-coups grâce à la commande optimale des dernières instants de la synchronisation. Une attention particulière a été dédiée aux détails pratiques d'implémentation de la stratégie en temps réel sur un prototype de Clio II équipé de boîte de vitesses robotisée. Les résultats expérimentaux montrent un écart remarquablement petit entre les trajectoires théoriques et mesurées ainsi qu'un niveau très élevé de confort.
\end{abstract}

\begin{abstract}
Observer-Based Optimal Control of Dry Clutch Engagement - Conventionally the control of dry clutch's engagement during a standing start in AMT vehicles is assured by look-up tables whose values are carefully chosen to produce a smooth synchronisation at the expense of a long slipping time. This article proposes, instead, a two phase approach: a first open-loop look-up table phase aiming to reduce the slipping time and a second observer-based optimal control phase assuring the engagement comfort. Particular attention has been given to the details of the on-line implementation on a Clio AMT prototype. Experimental results show both a close match between the predicted and the actual trajectories and a high level of comfort.
\end{abstract}

\section{INTRODUCTION}

Automated Manual Transmission vehicles are gaining momentum in the automotive industry due to their interesting combination of properties of the manual transmissions (i.e. lightness, higher efficiency, possibility of having a manual mode) and of the automatic transmissions with an hydraulic torque converter (i.e. ease of use and driving comfort).

Literature on dry clutch engagement control for AMT transmissions is quite ample and many different approaches have been proposed: quantitative feedback theory [11], fuzzy control [10, 12], model predictive control [1] and decoupling control [6]. Also optimal control of a dry clutch has been studied in some detail $[4,7,8]$ and [5].

When applying these solutions on an actual car one of the major hurdles to face is the integration of the driver's wish in the controller [2]. Traditionally this is archived employing look-up tables driven by the throttle pedal position specifying a reference value for the engine and clutch torque. These reference values are usually carefully chosen, as shown in the next section, to assure an open loop smooth standing start with the drawback of a long slipping time. This article 
proposes, instead, to use a reference aiming solely to shorten the synchronisation time and resort to finite time optimal trajectory planning at the end of the synchronisation in order to assure the comfort level.

\section{PROBLEM DESCRIPTION}

Engine torque is transmitted through the driveline to the wheels; friction forces between the wheels and the ground accelerate the vehicle mass. Since the internal combustion engine has a minimal rotational speed the clutch has to assure a smooth acceleration of the driveline speed from zero to engine speed during a standing start. Once the sliding speed has been reduced to zero further slipping is to be avoided and the clutch should behave like a simple linking element.

During the sliding phase the clutch torque, given by the Coulomb approximation of dry friction, is $\Gamma_{c} \approx$ $2 n \mu_{d} R_{c} F_{n}(x)$ [3] where $n$ is the clutch disks number, $\mu_{d}$ the dynamic friction coefficient, $R_{c}$ the mean radius of the friction pads on the clutch disks and $F_{n}(x)$ is the normal force applied on the friction surfaces, function of the hydraulic actuator position $x$. When the clutch is completely closed $\Gamma_{c} \approx \Gamma_{e}$ as the clutch simply transmits the engine torque.

In order to avoid a sudden change in the clutch torque at the synchronisation instant $t_{s}$ is therefore necessary to guarantee that $\Gamma_{c}\left(t_{s}^{-}\right) \approx \Gamma_{c}\left(t_{s}^{+}\right)=\Gamma_{e}\left(t_{s}\right)$. The value of $\Gamma_{e}\left(t_{s}\right)=\Gamma_{\text {driver }}$ is given by the driver's acceleration target expressed through the amount of throttle pedal depression. The limited control authority available on $\Gamma_{e}$ makes it very difficult to have important changes of this value in the proximity of $t_{s}$; therefore the standard jerk reduction strategy for an AMT vehicles during a standing start standing start calls for $\Gamma_{e}(t)=\Gamma_{\text {driver }}$ and $\Gamma_{c}(t) \approx \Gamma_{e}(t)$. Although the standard AMT jerk reduction strategy assures a very smooth standing start this is done at the price of a longer slipping time than what is commonly measured on an equivalent manual transmission vehicle. In this type of vehicles the clutch torque is directly controlled by the driver through the clutch pedal. In a typical manual transmission standing start the driver slowly closes the clutch reaching a $\Gamma_{c}>\Gamma_{e}$ causing the engine speed first to increase, peak off and finally dive until the synchronisation is reached. Manual transmission drivers learn to dose their actions in order to limit the engine speed peak value, its drop and the final jerk.

The jerk reduction strategy proposed in this article aims to reap the benefits of both strategies, i.e. short slipping time and smooth synchronisation, through an optimal trajectory planning of the final synchronisation phase, as shown in Figure 1. Since the slipping speed and the exact values of $\Gamma_{e}$ and $\Gamma_{c}$ are not available such a manoeuver is not feasible on a manual transmission car. The following sections details the optimal trajectory planning and its implementation on a Clio II $1.5 \mathrm{dCi}$ AMT vehicle.

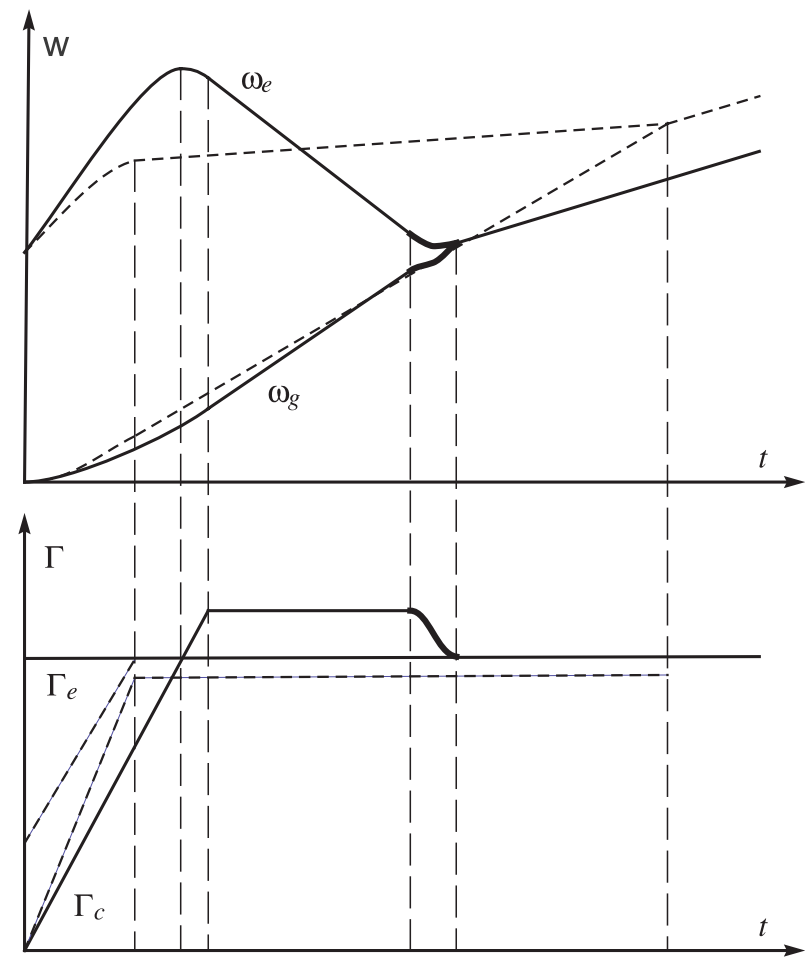

- proposed strategy

- - standard strategy

Figure 1

Comparison of the proposed and the standard standing standard strategy.

\section{OPTIMAL TRAJECTORY PLANNING}

\subsection{Simplified Driveline Model}

The simplified driveline model, introduced in [5], used for control design is:

$$
\left\{\begin{array}{l}
J_{e} \dot{\omega}_{e}=\Gamma_{e}-\Gamma_{c} \\
J_{g} \dot{\omega}_{g}=\Gamma_{c}-k \theta-\beta\left(\omega_{g}-\omega_{v}\right) \\
J_{v} \dot{\omega}_{v}=k \theta+\beta\left(\omega_{g}-\omega_{v}\right) \\
\dot{\theta}=\omega_{g}-\omega_{v}
\end{array}\right.
$$

where $\omega_{e}, \omega_{g}$ and $\omega_{v}$ are, respectively, the engine, gearbox end vehicle speed; $J_{e}, J_{g}$ and $J_{v}$ the engine, gearbox and vehicle inertias; $\theta$ is the transmission shaft torsion; $k$ and $\beta$ the transmission shaft stiffness and damping coefficients; $\Gamma_{e}$ and $\Gamma_{c}$ the engine and clutch torque.

\subsection{Optimisation Problem}

Normal look-up table open loop control is used for the initial part of the standing start allowing for user interaction, until the sliding speed is reduced to $y_{10}\left(\Gamma_{e}\right)$ where the optimal 
control is activated for a time interval $t_{s}-t_{0}$ at the end of which optimal synchronisation criteria are met.

Assuming a constant engine torque $\Gamma_{e}(t)=\Gamma_{e 0}$ and defining $y_{1}=\omega_{e}-\omega_{g}, y_{2}=\omega_{g}-\omega_{v}$ and $u=\dot{\Gamma}_{c}$, through simple algebraic manipulation (1) can be written as:

$$
\dot{x}=A x+B u
$$

where

$$
\begin{gathered}
x=\left[y_{1}, y_{2}, \theta, \Gamma_{e}, \Gamma_{c}\right]^{T} \\
A=\left[\begin{array}{ccccc}
0 & \beta / J_{g} & k / J_{g} & 1 / J_{e} & -1 / J_{t 1} \\
0 & -\beta / J_{t 2} & -k / J_{t 2} & 0 & 1 / J_{g} \\
0 & 1 & 0 & 0 & 0 \\
0 & 0 & 0 & 0 & 0 \\
0 & 0 & 0 & 0 & 0
\end{array}\right] B=\left[\begin{array}{l}
0 \\
0 \\
0 \\
0 \\
1
\end{array}\right] \\
J_{t 1}=\frac{J_{e} J_{g}}{J_{e}+J_{g}} \\
J_{t 2}=\frac{J_{g} J_{v}}{J_{g}+J_{v}}
\end{gathered}
$$

The control objective is reaching, starting from the state $x\left(t_{0}\right)$, a lurch free clutch's engagement, i.e. $\omega_{e}=\omega_{g}=\omega_{v}$ and $\dot{\omega}_{e}=\dot{\omega}_{g}=\dot{\omega}_{v}$ [4], while minimising the dissipated energy and actuator activity. Satisfying these conditions for the system (2) implies reaching the equilibrium point:

$$
x_{e q}=\left[0,0, \frac{1}{k} \frac{J_{v} \Gamma_{e}}{J_{e}+J_{g}+J_{v}}, \Gamma_{e}, \frac{\left(J_{g}+J_{v}\right) \Gamma_{e}}{J_{e}+J_{g}+J_{v}}\right]^{T}
$$

The problem lends itself naturally to a finite time optimal control formulation with prescribed initial and final states defining the triggering speed $y_{1} 0=y_{1}\left(t_{0}\right)$ and the most comfortable finite time trajectory.

\section{Problem statement}

Find $y_{0}$ and $u(t)$ which minimise the quadratic cost function

$$
J\left(y_{0}, u\right)=\int_{t_{0}}^{t_{s}}\left(x^{T} Q x+u^{t} R u\right) \mathrm{d} t
$$

under the following constraints

$$
\begin{gathered}
\dot{x}=A x+B u \quad x\left(t_{0}\right)=x_{0} \quad x\left(t_{s}\right)=x_{e q} \\
y_{1} \geq 0 \quad u \leq 0
\end{gathered}
$$

This optimal control problem is easily solved through discretisation and reconduction to a quadratic programming (QP) formulation. The two inequality constraints assure, respectively, the respect of the validity region of the simplified model and a higher level of comfort. Since $\Gamma_{c}\left(t_{0}\right)>\Gamma_{e}\left(t_{0}\right)>\Gamma_{c}\left(t_{s}\right)$ by design of the look-up table and definition of the equilibrium point, allowing $u(t)>0$ would result in a uncomfortable bump in the acceleration perceived by the driver at the activation of the optimal control.

\section{STRATEGY IMPLEMENTATION}

\subsection{Implementation Challenges}

The main challenges encountered while implementing the lurch avoidance strategy are the limited embarked computation power, the CAN delay, the non-uniform sampling of the engine speed and the clutch production dispersion and varying friction coefficient. The limitation in computing resources is discussed within the next section while the difficulties due to the CAN delay, the non-uniform sampling and the varying clutch's characteristics are, partially, solved through an unknown input observer. Finally a simple linear output feedback obtained by direct synthesis is employed to stabilise the system around the optimal trajectory.

\subsection{Computing Power Limitation}

In our previous article [4], using the dynamic lagrangian multipliers method, an analytical solution of a similar unconstrained problem has been found. Thus, ignoring the two linear constraints, such a solution could be easily adapted to the case at hand theoretically solving the computing power limitation due to its analytical nature. Unfortunately the linear system defining the initial costate conditions is ill conditioned requiring expensive variable precision algorithms for a reasonably precise solution; furthermore the costate dynamic equations are unstable making a real-time implementation very difficult.

Since the QP algorithm cannot be implemented online for both computation time and memory limitations it has to be moved off-line; this can be accomplished through a simplifying hypothesis on the initial states. During the final part of the sliding phase and before the synchronisation takes place, it can be safely assumed that the oscillations dues to the initial torsion of the driveline have been sufficiently damped out, i.e. $y_{2}\left(t_{0}\right)=0$. This assumption allows to define the initial state of the driveline as functions of the initial clutch torque $\Gamma_{c 0}$, the constant engine torque $\Gamma_{e}$ and the activation speed $y_{10}$.

$$
x_{0}=\left[y_{10}, 0, \frac{J_{v} \Gamma_{c 0}}{k\left(J_{g}+J_{v}\right)}, \Gamma_{e 0}, \Gamma_{c 0}\right]^{T}
$$

Sampling the $\left\{\left(t \times \Gamma_{e 0} \times \Gamma_{c 0}\right), t \in\left[t_{0} t_{f}\right], \Gamma_{e 0} \in\left[\Gamma_{e m i n} \Gamma_{e m a x}\right]\right.$, $\left.\Gamma_{c 0} \in\left[\Gamma_{c f}\left(\Gamma_{e 0}\right) \Gamma_{c m a x}\right]\right\} \subset \mathbb{R}^{3}$ space the activation speed $y_{10}\left(\Gamma_{e 0}, \Gamma_{c 0}\right)$, the optimal control $\Gamma_{c}^{*}\left(\Gamma_{e 0}, \Gamma_{c 0}, t\right)$ and the optimal sliding speed trajectory $y_{1}^{*}\left(\Gamma_{e 0}, \Gamma_{c 0}, t\right)$ can be stored in look-up tables. To further simplify information retrieval $\Delta \Gamma_{c}=\Gamma_{c 0}-\Gamma_{c f}\left(\Gamma_{e 0}\right)$ is defined orthogonalising the space coordinates. The on-line algorithm simply retrieves through multidimensional interpolation the needed values. Sampling intervals are detailed in Table 1 . The 4320 samples of 32 bits each occupy $135 \mathrm{~Kb}$ of memory space. 
TABLE 1

Sampling details

\begin{tabular}{c|c|c|c|c}
\hline & $\min$ & $\max$ & sampl. & \# smp \\
\hline$t[\mathrm{~s}]$ & 0 & 0.6 & 0.01 & 60 \\
\hline$\Gamma_{e}[\mathrm{Nm}]$ & 30 & 120 & 10 & 9 \\
\hline$\Delta \Gamma_{c}[\mathrm{Nm}]$ & 5 & 40 & 5 & 8 \\
\hline Total & & & & 4320 \\
\hline
\end{tabular}

\subsection{Unknown Input Observer and State Predictor}

Engine speed is measured counting the teeth of the crankup wheel; each revolution of the crankshaft when the first piston reaches the upper dead point the engine control unit updates the engine speed value in the CAN register. This information, whether updated or not, is broadcasted on the bus every $10 \mathrm{~ms}$ so that the gearbox control unit has no trivial way of telling apart a missed update from a constant engine speed. Furthermore treatment and communication delays create an offset $\tau_{0}=40 \mathrm{~ms}$ between the engine speed and the gearbox speed which is directly measured by the gearbox control unit.

Taking in consideration only the engine inertia the simplified system becomes

$$
\begin{aligned}
& \dot{\omega}_{e}(t)=\frac{1}{J_{e}}\left(\Gamma_{e}(t)-\Gamma_{c}(t)\right) \\
& \dot{\Gamma}_{c}(t)=u(t)
\end{aligned}
$$

where $u(t)$ is an unknown input with $|u(t)| \leq u_{\max }$. The measured outputs are

$$
\begin{aligned}
& \bar{\omega}_{e}(t)=\omega_{e}\left(t-\tau_{0}\right)+\varepsilon\left(t-\tau_{0}\right) \\
& \bar{\Gamma}_{e}(t)=G\left(\Gamma_{e}(t)\right)
\end{aligned}
$$

where $\varepsilon$ is the noise due to the time varying sampling and $G\left(\Gamma_{e}(t)\right)$ is the engine torque estimation generated by the engine control unit. Having defined this the following result, justified in the appendix, can be enounced:

Theorem 1 Given (4) with (5) as measured outputs and the unknown input delayed observer

$$
\begin{aligned}
\dot{\hat{\omega}}_{e}\left(t-\tau_{0}\right)= & \frac{1}{J_{e}}\left(\bar{\Gamma}_{e}\left(t-\tau_{0}\right)-\hat{\Gamma}_{c}\left(t-\tau_{0}\right)\right) \\
& +k_{1}\left(\bar{\omega}_{e}(t)-\hat{\omega}_{e}\left(t-\tau_{0}\right)\right) \\
\dot{\hat{\Gamma}}_{c}\left(t-\tau_{0}\right)= & k_{2}\left(\bar{\omega}_{e}(t)-\hat{\omega}_{e}\left(t-\tau_{0}\right)\right)
\end{aligned}
$$

the following general attenuation inequality on its joint estimation error $w=\left[\omega_{e}-\hat{\omega}_{e}, \Gamma_{c}-\hat{\Gamma}_{c}\right]^{T}$ holds true

$$
\|w\|_{\mathcal{L}_{2}} \leq \gamma_{1}\left\|\left[\begin{array}{c}
\tilde{\Gamma}_{e} \\
u_{\max }
\end{array}\right]\right\|_{\mathcal{L}_{2}}+\gamma_{2}\|\epsilon\|_{\mathcal{L}_{2}}+\beta
$$

where $\tilde{\Gamma}_{e}$ is the estimation error on the engine torque made by the engine control unit and

$$
\gamma_{1} \leq \frac{-\lambda_{\max }(A)}{J_{e}^{2} \lambda_{\min }^{2}(A)} \quad \gamma_{2} \leq \frac{-k_{1}^{2} \lambda_{\max }(A)}{\lambda_{\min }^{2}(A)}
$$

$$
\beta=\|w(0)\| \sqrt{\frac{-\lambda_{\max }(A)}{2 \lambda_{\min }^{2}(A)}}
$$

Since $\min \left\{\lambda_{\max }(A) / \lambda_{\min }(A)\right\}=1$ for $\lambda=\lambda_{\max }(A)=$ $\lambda_{\min }(A)$ the previous expressions can be further simplified

$$
\gamma_{1}=-\frac{1}{J_{e} \lambda} \quad \gamma_{2}=-4 \lambda \quad \beta=\|w(0)\| \sqrt{\frac{-1}{2 \lambda}}
$$

Unsurprisingly input noise and initial state coefficients, namely $\gamma_{1}$ and $\beta$, decrease for large $|\lambda|$ while the output noise coefficient increases. Given a value of the noise level an optimal choice of the pole placement can thus be made.

Since the result of the observer is delayed by $\tau_{0}$ a simple state predictor using a backward rectangular approximation, i.e. one step of Euler's method, is used to estimate $\hat{x}(t)$

$$
\hat{x}(t) \approx \hat{x}\left(t-\tau_{0}\right)+\frac{1}{J_{e}}\left(\bar{\Gamma}_{e}\left(t-\tau_{0}\right)-\hat{\Gamma}_{c}\left(t-\tau_{0}\right)\right)
$$

$\hat{\omega}_{e}(t)$ is directly used in the trajectory stabilisation loop while $\hat{\Gamma}_{c}$ is simply used for calculating a fixed correction coefficient at the activation of the optimal control in order to avoid a possibly instable feedback.

\subsection{Final Control Structure}

As previously said the final control is composed of two phases: during the first $\Gamma_{e}(t)$ and $\Gamma_{c}(t)$ are defined by openloop look-up tables aiming to reduce the sliding speed ${ }^{(1)}$. During this phase the observer is active and can converge to a good estimation of $\hat{\Gamma}_{c}$. The one way only transition to the second phase is controlled by the $y_{1}(t) \leq y_{10}\left(\Gamma_{e}(t), \hat{\Gamma}_{c}(t)\right)$ condition. During the second phase $\Gamma_{e}(t)=\Gamma_{e 0}$ and $\Gamma_{c}(t)=\Gamma_{c}^{*}(t)+\Gamma_{s t a b}(t)$ where $\Gamma_{c}^{*}(t)$ is the interpolation of the optimal control and $\Gamma_{\text {stab }}(t)$ is the linear controller output tracking the optimal reference trajectory $y_{1}^{*}(t)$ using the delay-free engine speed estimation $\hat{\omega}_{e}$. After $0.6 \mathrm{~s}$ the final conditions (3) are met and the clutch is completely closed thus ending the standing start manoeuver.

\section{EXPERIMENTAL RESULTS}

The lurch avoidance strategy presented in the previous sections has been successfully implemented and tested on a Clio II AMT $1.5 \mathrm{dCi}$ prototype whose standard gearbox control unit has been substituted with a PC equipped with a rapid prototyping dSpace DSP card. Figures 2, 3 and 4 show the measures recorded during a standing start on a test track in Renault Technical Centre of Lardy.

As shown in Figure 3, the synchronisation is reached just after $36.9 \mathrm{~s}$, a little earlier than the predicted $37 \mathrm{~s}$. Ideal

(1) Since the look-up table values have to be chosen only to assure a short slipping time calibration is much easier since no speed/comfort compromise has to be settled. 


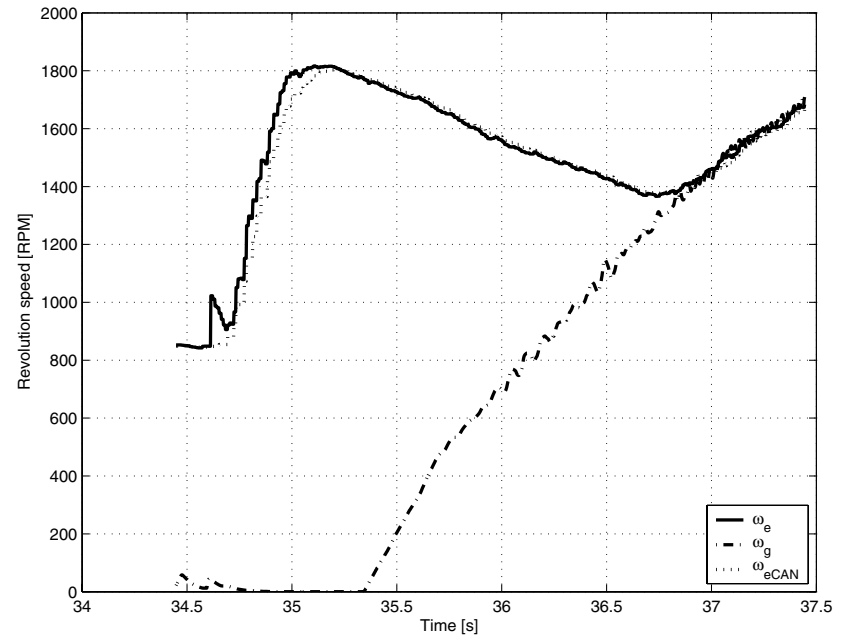

Figure 2

Standing start on a flat track, $\omega_{e}$ is the predicted engine speed, $\omega_{e C A N}$ is the delayed CAN information and $\omega_{g}$ is the gearbox speed. Optimal control has been activated just after $36.4 \mathrm{~s}$.

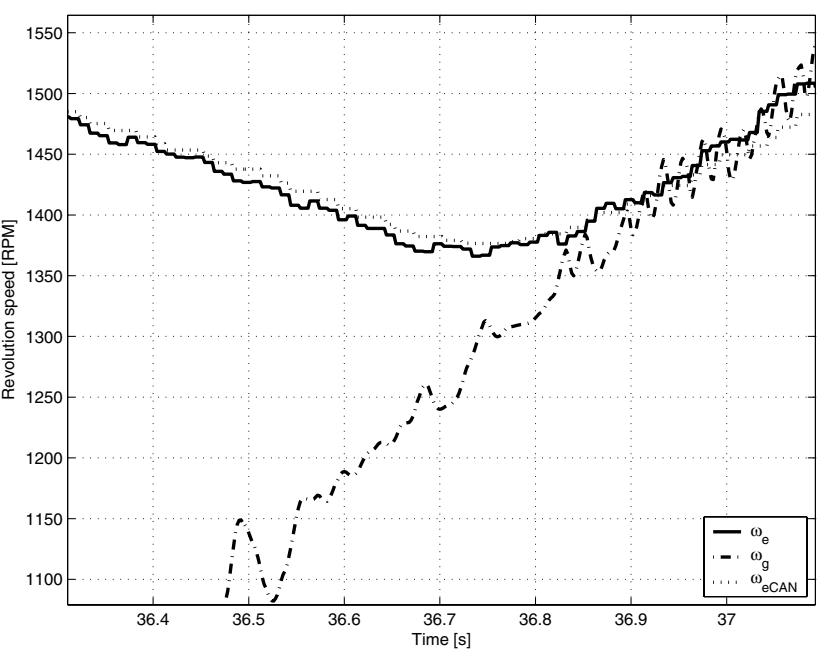

Figure 3

Detail of previous image showing the effect of the optimal control. synchronisation boundary conditions are met and no oscillations are generated. The small change in engine speed at about $37.3 \mathrm{~s}$ shown in Figure 2 is due to the engine control unit. Figure 4 shows how the measured sliding speed, drawn with a slash-dotted line, closely matches the optimal trajectory, drawn with a solid line reaching zero sliding speed with a zero derivative. The dashed line shows the sliding speed trajectory that would have been followed if no partial reopening of the clutch was made, i.e. the control system remained in the first phase. Interestingly this is also the trajectory followed by a manual transmission driver showing the inherent trade-off between synchronisation speed and engagement comfort. Figure 5 shows the estimation of the engine torque by the engine control unit, the requested clutch torque issued by the controller and the estimated torque transmitted by the clutch. The throttle pedal position, Figure 6, as usual in a normal standing start, does not change during the engagement. If this condition is not verified during the open loop phase the clutch torque setting point is changed accordingly and a new optimal synchronisation trajectory is selected; on the other hand if the pedal movement is made during the final instants the feedback loop will track of the old optimal clutch's sliding speed trajectory. In this case only $\omega_{e}\left(t_{f}\right)=\omega_{g}\left(t_{f}\right)$ and $\dot{\omega}_{e}\left(t_{f}\right)=\dot{\omega}_{g}\left(t_{f}\right)$ conditions are assured to be satisfied; the difference relative to the ideal synchronisation conditions depends on the amplitude of the disturbance but normally are small enough to not impact the comfort level.

In order to plan the optimal trajectories a complete knowledge of the parameters of the simplified model has been assumed. These values are all fixed by mechani-

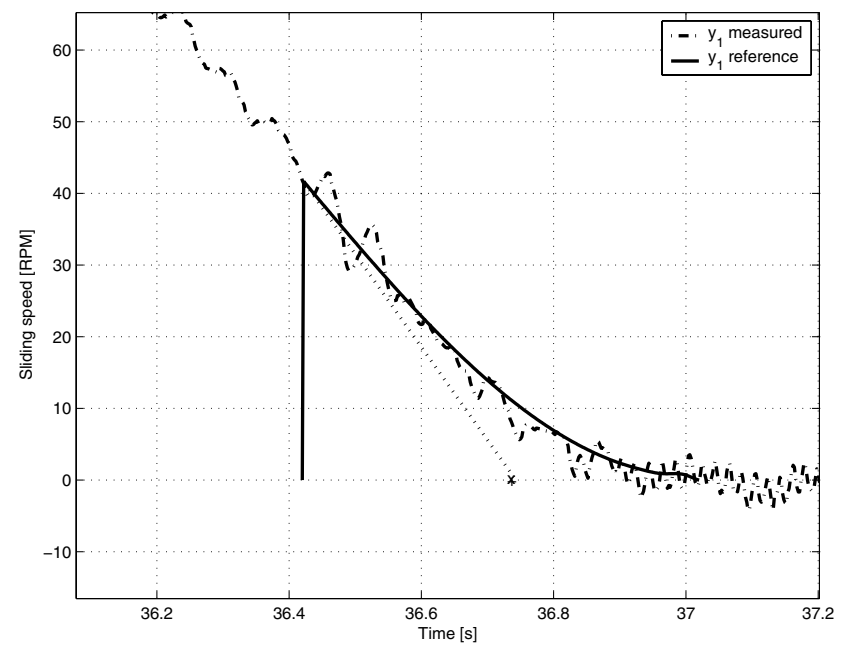

Figure 4

Measured clutch sliding speed during the final phase of the engagement compared to the optimal trajectory. The dotted line shows the sliding speed trajectory in absence of optimal control.

cal elements specifications with quite tight tolerances but for two exceptions: clutch characteristics and vehicle inertia $J_{v}$ which, depending on the car load, can have dramatic changes. While an observer has been introduced to compensate for the clutch variations, only the trajectory stabilisation output feedback is responsible for assuring the engagement in the second case. In order to test the robustness of the 


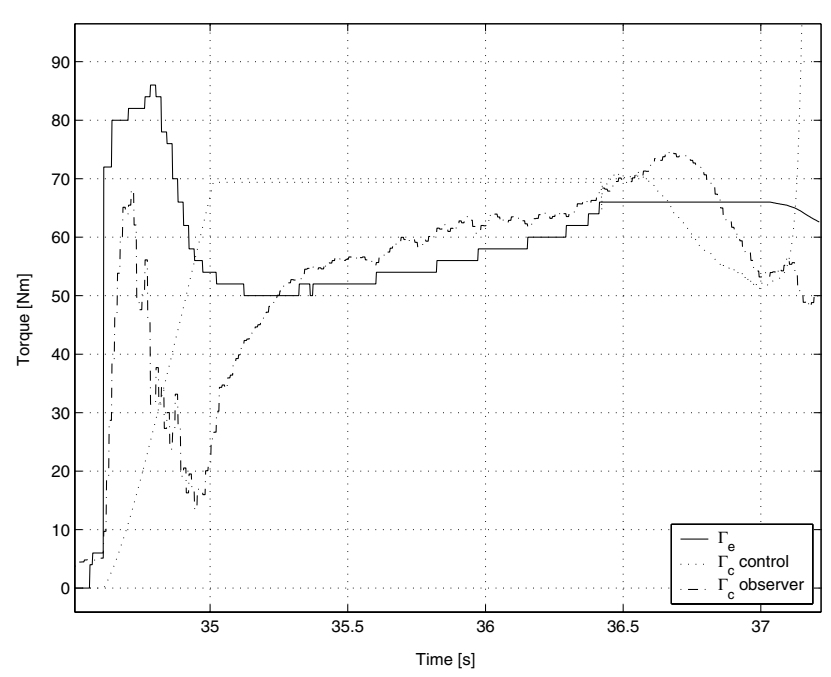

Figure 5

Estimated engine torque, clutch torque set point issued by the controller and estimated clutch torque during the standing start.

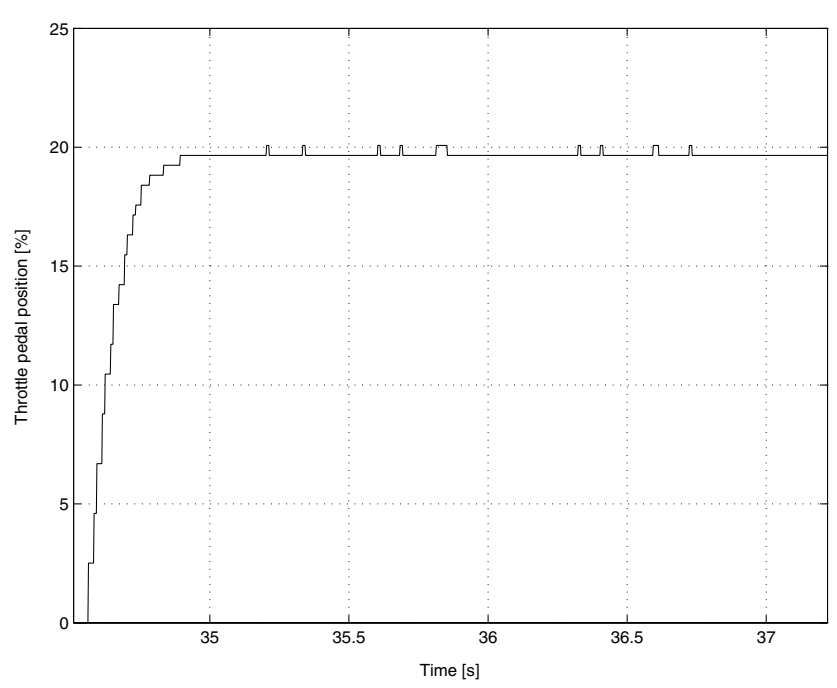

Figure 6

Throttle pedal position during the standing start.

stabilisation loop the car has been loaded with a ballast in excess of $400 \mathrm{~kg}$ without any noticeable effect on the standing start comfort but for a slight increase of the slipping time during the open-loop phase.

\section{CONCLUSIONS}

A lurch avoidance strategy aiming to assure an optimal level of engagement comfort while reducing the clutch slipping time has been presented. The challenges faced during its implementation and the corresponding proposed solutions have been discussed in Section 3. Particular attention has been given to the design of an unknown input observer with limited estimation error. Finally experimental results and their interpretation have been given in the last section. The proposed control structure assure a close tracking of the optimal slipping speed trajectory even in presence of a heavy ballast load.

\section{REFERENCES}

1 Bemporad, A., Borrelli, F., Glielmo, L., and Vasca, F. (2001) Hybrid control of dry clutch engagement. Proc. of European Control Conf.

2 Canudas de Wit, C., Béchart, H., Claeys, X., Dolcini, P., and Martinez, J.-J. (2005) Fun-to-drive by feedback. Int. J. Control, 11, 4-5, 353-383.

3 Canudas, de Wit C., Petersen, M.L. and Shiriaev, A. (2003) A new nonlinear observer for tire/road distributed contect friction. Proc. of the Conf. on Decision and Control.

4 Dolcini, P., Canudas, de Wit C., and Béchart, H. (2005) Improved optimal control of dry clutch engagement. Proc. 16th IFAC World Conference Prague.

5 Dolcini, P., Canudas, de Wit C., and Béchart, H. (2005) Observer based optimal control of dry clutch engagement. Proc. 16 IFAC World Conference Prague.

6 Garofalo, F., Glielmo, L., Iannelli, L., and Vasca, F. (2001) Smooth engagement of automotive dry clutch. Proc. of the 40th IEEE CDC, pp. 529-534.

7 Garofalo, F., Glielmo, L., Iannellli, L. and Vasca, F. (2002) Optimal tracking for automotive dry clutch engagement. Proc. of the 15th IFAC congress.

8 Glielmo, L. and Vasca, F. (2000) Optimal control of dry clutch engagement. SAE, (2000-01-0837).

9 Khalil, H.K. (2002) Nonlinear systems third edition, Patience Hall.

10 Shuiwen, S., Anlin, G., Bangjie, L., Tianyi, Z. and Juexin, F. (1995) The fuzzy control of a clutch of an elctronically controlled automatic mechanical transmission. JSAE Technical Paper Series, 9530805.

11 Sliker, J. and Loh, R.N.K. (1996) Design of robust vehicle launch control systems. IEEE Trans. Control System Technol., 44, 326-335.

12 Tanaka, H. and Wada, H. (1995) Fuzzy control of engagement for automated manual transmission. Vehicle Syst. Dyn., 24, 365-366. 


\section{PROOF OF THEOREM}

Lemma 1 The LTI system:

$$
\left\{\begin{array}{l}
\dot{x}=A x+B u \\
y=C x+D u
\end{array}\right.
$$

is finite-gain $\mathcal{L}_{p}$ stable for each $p \in[1, \infty]$ if $A$ is Hurwitz. Moreover $\|y\|_{\mathcal{L}_{p}} \leq \gamma\|u\|_{\mathcal{L}_{p}}+\beta$ is satisfied with:

$$
\begin{gathered}
\gamma=\|D\|_{2}+\frac{2 \lambda_{\text {max }}^{2}(P)\|B\|_{2}\|C\|_{2}}{\lambda_{\text {min }}(P)} \\
\beta=\rho\|C\|_{2}\left\|x_{0}\right\| \sqrt{\frac{\lambda_{\text {max }}(P)}{\lambda_{\text {min }}(P)}}
\end{gathered}
$$

where

$$
\rho= \begin{cases}1, & \text { if } p=\infty \\ \left(\frac{2 \lambda_{\max }(P)}{p}\right)^{1 / p}, & \text { if } p \in[1, \infty)\end{cases}
$$

and $P$ is the solution of the Lyapunov equation $P A+$ $A^{T} P=-I$.

Proof 1 This Lemma is the Corollary 5.2 of the Theorem 5.1 page 202 of [9].

Theorem 2 Given the perturbed linear system

$$
\begin{aligned}
& \dot{z}=A x+B u+W_{1} \epsilon_{1} \\
& y=C x+W_{2} \epsilon_{2}
\end{aligned}
$$

with $(A, C)$ observable and a matrix $K$ such that $A-K C$ has real negative eigenvalues with linearly independent associated eigenvectors, the Luenberger observer

$$
\begin{aligned}
& \dot{\hat{x}}=A \hat{x}+B u+K(x-\hat{x}) \\
& \hat{y}=C \hat{x}
\end{aligned}
$$

has an estimation error $\tilde{x}=x-\hat{x}$ limited by

$$
\|\tilde{x}\|_{\mathcal{L}_{p}} \leq \gamma_{1}\left\|\epsilon_{1}\right\|_{\mathcal{L}_{p}}+\gamma_{2}\left\|\epsilon_{2}\right\|_{\mathcal{L}_{p}}+\beta
$$

where

$$
\gamma_{1}=-\frac{\lambda_{\max }}{\lambda_{\min }^{2}}\left\|W_{1}\right\|_{\mathcal{L}_{p}} \quad \gamma_{2}=-\frac{\lambda_{\max }}{\lambda_{\min }^{2}}\left\|K W_{2}\right\|_{\mathcal{L}_{p}}
$$

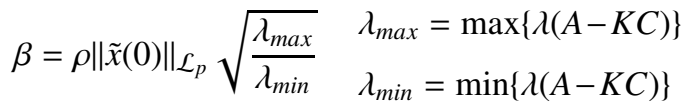

Proof 2 By simple substitution

$$
\dot{\tilde{x}}=(A-K C) \tilde{x}+W_{1} \epsilon_{1}-K W_{2} \epsilon_{2}
$$

By hypothesis $A-K C$ is diagonalisable, i.e. it exists a base transformation $\tilde{x}=T z$ such that

$$
\dot{z}=D z+\bar{B}_{1} \epsilon_{1}+\bar{B}_{2} \epsilon_{2}
$$

with $D=T^{-1}(A-K C) T$ is a diagonal matrix, $\bar{B}_{1}=T^{-1} W_{1}$ and $\bar{B}_{2}=T^{-1} K W_{2}$. Moreover $T$ has the eigenvectors of $A-K C$ as columns which are defined but for a constant multiplier allowing to assume $\|T\|_{2}=1$ without any loss of generality.

Since $P=-2 D^{-1}$ is the solution of the Lyapunov equation $D^{T} P+P D=-I$ the following relation holds:

$$
\begin{aligned}
& \lambda_{\text {max }}(P)=-1 /\left(2 \lambda_{\text {min }}(A-K C)\right) \\
& \lambda_{\text {min }}(P)=-1 /\left(2 \lambda_{\text {max }}(A-K C)\right)
\end{aligned}
$$

Using the superposition principle, the Lemma 1 and the eigenvalues relation A.2 on system A.1 we have:

$$
\|z\|_{\mathcal{L}_{p}} \leq \gamma_{1}\left\|\epsilon_{1}\right\|_{\mathcal{L}_{p}}+\gamma_{2}\left\|\epsilon_{2}\right\|_{\mathcal{L}_{p}}+\beta
$$

with

$$
\begin{array}{ll}
\gamma_{1}=-\frac{\lambda_{\text {max }}}{\lambda_{\text {min }}^{2}}\left\|\bar{B}_{1}\right\|_{\mathcal{L}_{p}} & \gamma_{2}=-\frac{\lambda_{\text {max }}}{\lambda_{\text {min }}^{2}}\left\|\bar{B}_{2}\right\|_{\mathcal{L}_{p}} \\
\beta=\rho\|z(0)\| \sqrt{\frac{\lambda_{\text {max }}}{\lambda_{\text {min }}}} & \lambda_{\text {max }}=\max \{\lambda(D)\} \\
\lambda_{\text {min }}=\min \{\lambda(D)\}
\end{array}
$$

Since $\lambda(D)=\lambda(A-K C)$ and $\|\tilde{x}\|_{\mathcal{L}_{p}}=\|T z\|_{\mathcal{L}_{p}} \leq\|T\|_{2}\|z\|_{\mathcal{L}_{p}}=$ $\|z\|_{\mathcal{L}_{p}}$ we have the thesis.

\section{Copyright $\odot 2007$ Institut français du pétrole}

Permission to make digital or hard copies of part or all of this work for personal or classroom use is granted without fee provided that copies are not made or distributed for profit or commercial advantage and that copies bear this notice and the full citation on the first page. Copyrights for components of this work owned by others than IFP must be honored. Abstracting with credit is permitted. To copy otherwise, to republish, to post on servers, or to redistribute to lists, requires prior specific permission and/or a fee: Request permission from Documentation, Institut français du pétrole, fax. +33147527078 , or revueogst@ifp.fr. 